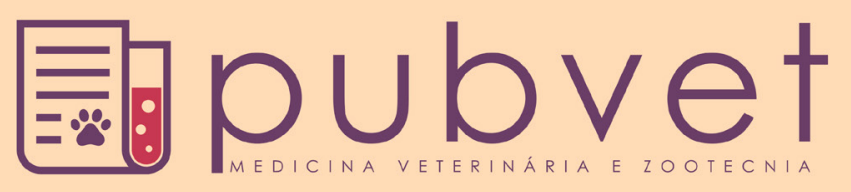

HTTP://DX.DOI.ORG/10.22256/PUBVET.V11N7.727-736

\title{
Desempenho de bovinos de corte alimentados com diferentes forragens e alojados em baias individuais ou coletivas
}

\author{
Sergio Antonio Schwartz Custodio'ㅗ Diego Azevedo Leite da Silva ${ }^{2}$, Kaique Moreira Dias ${ }^{3}$, \\ Marcus Paulo Pereira Tomaz ${ }^{2}$, Rodrigo de Oliveira Goulart ${ }^{2}$, Eduardo Rodrigues de \\ Carvalho $^{4^{*}}$
}

${ }^{1}$ Mestre em Zootecnia pelo IF Goiano, Campus Rio Verde, Rio Verde-GO, Brasil. E-mail: sergio.custodio13@gmail.com ${ }^{2}$ Discente do Curso de Agronomia do IF Goiano, Campus Iporá - GO, Brasil, bolsista do CNPq. E-mail: diego.pedepato@gmail.com ${ }^{3}$ Discente do Curso de Agronegócio do IF Goiano, Campus Iporá - GO, Brasil, bolsista do CNPq.E-mail: kaique18dias@gmail.com ${ }^{2}$ Discente do Curso de Agronomia do IF Goiano, Campus Iporá - GO, Brasil, bolsista do CNPq. E-mail: marcus paulo370@hotmail.com ${ }^{2}$ Discente do Curso de Agronomia do IF Goiano, Campus Iporá - GO, Brasil, bolsista do CNPq).E-mail: rodrigogoulart007@gmail.com ${ }^{4}$ Professor de Zootecnia do IF Goiano, Campus Iporá - GO Brasil. E-mail: eduardo.carvalho@ifgoiano.edu.br *Autor para correspondência.

RESUMO. As forragens cumprem um papel essencial no desempenho de bovinos de corte em confinamento. Vinte e quatro machos não castrados Red Norte $\times$ Nelore com peso corporal (PC) inicial médio de $439,8 \mathrm{~kg}$ e 21,7 meses de idade foram distribuídos em três grupos experimentas e alojados em baias individuais (doze animais) ou coletivas (doze animais em três baias) na Fazenda-Escola do IF Goiano (Campus Iporá). O experimento teve duração de 84 dias (14 dias para adaptação e 70 dias para coleta de dados). Alimentaram-se os animais uma vez ao dia com dietas à base de cana-de-açúcar in natura (Ci), silagem de cana (SC) ou silagem de milho (SM) como fontes de forragem. Avaliouse o consumo de matéria seca (CMS) diariamente pela diferença entre a quantidade oferecida menos a recusada, e registrou-se o PC dos animais a cada 14 dias após jejum de sólidos de doze horas. Não houve efeito $(\mathrm{P}>0,05)$ da fonte de forragem sobre o CMS nos animais alojados nas baias individuais, assim como não houve resposta $(\mathrm{P}>0,05)$ da fonte de forragem sobre o desempenho corporal. As fontes de forragem não alteraram $(\mathrm{P}>0,05)$ as características da carcaça. Os animais alojados nas baias individuais aumentaram $(\mathrm{P}<$ $0,05)$ o peso do trato gastrintestinal vazio $(11,9 \mathrm{~kg})$, comparados aos animais alojados nas baias coletivas $(10,2 \mathrm{~kg})$. Concluiu-se que as três fontes de forragem ( $\mathrm{Ci}, \mathrm{SC}$ e $\mathrm{SM})$ podem ser recomendadas na alimentação de bovinos de corte em confinamento.

Palavras chave: cana-de-açúcar, consumo, peso corporal, Red Norte, silagem de milho

\section{Performance of beef cattle fed different forages and housed in individual or collective pens}

ABSTRACT. Forages play a key role on the performance of beef cattle in feedlot systems. Twenty-four non-castrated Red Norte $\times$ Nelore males with an average initial body weight (BW) of $439.8 \mathrm{~kg}$ and 21.7 months of age were distributed in three experimental groups, and housed either in individual or collective pens (twelve animals in individual pens and twelve in three collective pens) at the School-Farm of IF Goiano (Iporá Campus). The experiment lasted 84 days (14 days for adaptation and 70 days for data collection). Animals were fed once daily with diets containing in natura sugar cane (ISC), sugar cane silage (SCS) or corn silage (CS) as sources of forage. Feed refusals were measured daily and dry matter intake (DMI) was determined by difference. BW was recorded every two weeks after a twelve-hour fasting period. There was no effect $(\mathrm{P}>0.05)$ of source of forage on DMI in animals housed in individual pens, as well as there was no response $(\mathrm{P}>0.05)$ of source of forage on growth performance. The three sources of forage did not alter $(\mathrm{P}>0.05)$ 
carcass traits. Animals housed in individual pens increased $(\mathrm{P}<0.05)$ empty gastrointestinal tract weight $(11.9 \mathrm{~kg})$ compared with animals housed in collective pens $(10.2 \mathrm{~kg})$. The three sources of forage (ISC, SCS and CS) can be recommended for beef cattle feeding in feedlot systems.

Keywords: Body weight, corn silage, intake, Red Norte, sugar cane

\section{Características productivas de bovinos de engorde alimentados con diferentes forrajes y estabulados de forma individual o colectiva}

RESUMEN: Los forrajes desempeñan un papel esencial en el rendimiento productivo de los bovinos de carne en confinamiento. Veinticuatro machos no castrados Red Norte $\times$ Nelore con peso corporal (PC) inicial promedio de 439,8 kg y 21,7 meses de edad fueron distribuidos en tres grupos experimentales y estabulados en corrales individuales (doce animales) o colectivos (doce animales en tres corrales) en la Finca-Escuela del IF Goiano (Campus Iporá). El experimento tuvo una duración de 84 días (14 días para adaptación y 70 días para colectar datos). Se alimentaron los animales una vez al día con dietas a base de caña de azúcar in natura (Ci), ensilaje de caña (EC) o ensilaje de maíz (EM) como fuentes de forraje. Se evaluó el consumo de materia seca (CMS) diariamente por la diferencia entre la cantidad ofrecida menos la cantidad rechazada, y se registró el PC de los animales a cada 14 días después de un ayuno de sólidos de doce horas. No hubo efecto $(\mathrm{P}>0,05)$ de la fuente de forraje sobre el CMS en los animales estabulados de forma individual, así como no hubo respuesta $(\mathrm{P}>0,05)$ de la fuente de forraje sobre el desempeño corporal. Las fuentes de forraje no alteraron $(\mathrm{P}>0,05)$ las características de la canal. Los animales estabulados individualmente aumentaron $(\mathrm{P}<0,05)$ el peso del tracto gastrointestinal vacío $(11,9 \mathrm{~kg})$, comparados a los animales estabulados colectivamente $(10,2 \mathrm{~kg})$. Se concluyó que las tres fuentes de forraje (Ci, EC y EM) pueden ser recomendadas en la alimentación de bovinos de engorde estabulados.

Palabras clave: caña de azúcar, consumo, ensilado de maíz, peso corporal, Red Norte

\section{Introdução}

A sazonalidade na produção de forragem ainda é um dos principais entraves para o crescimento da produtividade da pecuária de corte, na medida em que determina elevada idade de abate e resulta em uma baixa eficiência da atividade (ANUALPEC, 2016, Moreira and Prado, 2010).

A forragem possui importante papel na formulação de rações para bovinos de corte em confinamento, uma vez que o custo com alimentação contribui com cerca de $70 \%$ do custo da terminação e exerce influência sobre $o$ desempenho animal (Brondani et al., 2004, Campos et al., 2010, Moreira et al., 2004). Decréscimos no consumo de matéria seca (CMS) de forragens ocorrem em função da alta concentração de fibra em detergente neutro (FDN), baixa palatabilidade, redução da taxa de passagem pelo rúmen e desbalanceamento no suprimento de aminoácidos e energia aos tecidos do animal (Mertens, 1987, Huhtanen et al., 2007, Berchielli et al., 2011).
No Brasil existem várias opções de forragens para utilização em confinamentos, dentre elas a silagem de milho e a cana-de-açúcar. Apesar da silagem de milho conter um valor nutritivo mais elevado comparado à cana-de-açúcar (Velho et al., 2007, Zopollatto et al., 2009), a segunda tem sido utilizada na forma in natura devido às suas características desejáveis, tais como alto rendimento de matéria seca (MS) por unidade de área (Freitas et al., 2006), baixo risco na sua utilização como forragem, baixo custo por unidade de MS produzida e conservação do valor nutricional por um longo período após a sua maturação (Azevêdo et al., 2003, Costa et al., 2005). No entanto, em confinamentos com elevado número de animais, o corte e trituração diários da cana-de-açúcar podem se tornar um empecilho, fazendo com que a ensilagem seja uma opção interessante.

Objetivou-se neste trabalho determinar o efeito da alimentação da cana-de-açúcar in natura (Ci), silagem de cana (SC) ou silagem de milho (SM) sobre o desempenho de 24 bovinos machos não castrados Red Norte $\times$ Nelore em confinamento. 
Testou-se a hipótese de que fontes de forragem ( $\mathrm{Ci}, \mathrm{SC}$ ou $\mathrm{SM}$ ) incluídas em diferentes proporções na MS da ração não exerçam influência sobre o desempenho animal, desde que os níveis nutricionais das dietas sejam semelhantes.

\section{Material e Métodos}

O presente estudo foi conduzido na Fazenda Experimental do IF Goiano (Campus Iporá) entre 30 de junho a 15 de setembro de 2014, com duração de 84 dias (14 dias de adaptação dos animais às instalações e dietas experimentais e 70 dias de período experimental). Foram utilizados 24 bovinos machos não castrados Red Norte $\times$ Nelore com peso corporal (PC) médio inicial de $439,8 \pm 26,2 \mathrm{~kg}$ e idade média de $21,7 \pm 2,7$ meses.

No primeiro dia da fase de adaptação os animais foram desvermifugados com Fenbendazole a $10 \%$ por via oral e receberam aplicação contra ectoparasitas à base de $5 \%$ de Cipermetrina, $2,5 \%$ de Clorpirifós e $1 \%$ de Butóxido de Piperonila ao longo da linha dorsalcaudal. Após estas aplicações, os animais foram classificados quanto ao $\mathrm{PC}$, distribuídos em três grupos experimentais de acordo com a fonte de forragem (Ci, SC ou $\mathrm{SM}$ ) e alojados em baias individuais (doze animais) ou coletivas (doze animais em três baias).

Os animais foram alimentados uma vez ao dia entre 05:00 e 07:00 horas com quantidades ajustadas diariamente para se obter entre 10 a $15 \%$ de sobras, a fim de se garantir o máximo consumo voluntário de MS. A composição e valor nutricional das três rações experimentais estão descritas na Tabela 1. Durante a ensilagem da cana-de-açúcar adicionou-se inoculante bacteriano (dois gramas de produto comercial/tonelada de matéria natural) à base de Lactobacillus plantarum (cepas CH6072 e L286) para redução da produção de etanol durante o processo fermentativo (Zopollatto et al., 2009).

As três dietas foram formuladas para conterem concentrações semelhantes de FDN e proteína bruta $(\mathrm{PB})$, e balanceadas para atender as exigências nutricionais diárias de bovinos de corte em confinamento com ganho de peso esperado de $1,8 \mathrm{~kg} / \mathrm{dia}$ (NRC, 2000). Todos os protocolos experimentais foram aprovados pela Comissão de Ética no Uso de Animais (CEUA) do IF Goiano (parecer $n^{\circ} 1 / 2014$ ).

Tabela 1. Ingredientes e composição nutricional das dietas experimentais ${ }^{1}$

\begin{tabular}{|c|c|c|c|}
\hline Ingredientes, $\%$ na MS & $\mathrm{Ci}$ & $\mathrm{SC}$ & SM \\
\hline Cana-de-açúcar in natura (Ci) & 22,0 & - & - \\
\hline Silagem de cana (SC) & - & 22,0 & - \\
\hline Silagem de milho (SM) & - & - & 32,0 \\
\hline MDPS $^{2}$ & 24,0 & 24,0 & 26,0 \\
\hline Milho triturado & 40,5 & 40,5 & 29,5 \\
\hline Farelo de soja & 10,0 & 10,0 & 9,0 \\
\hline Ureia protegida $^{3}$ & 1,0 & 1,0 & 1,0 \\
\hline Núcleo vitamínico mineral $^{4}$ & 2,5 & 2,5 & 2,5 \\
\hline \multicolumn{4}{|l|}{ Composição nutricional } \\
\hline MS, \% & $67,60 \pm 3,28$ & $63,88 \pm 1,71$ & $57,20 \pm 1,97$ \\
\hline $\mathrm{PB}^{5}, \%$ da $\mathrm{MS}$ & $13,46 \pm 1,06$ & $14,75 \pm 0,87$ & $13,86 \pm 0,33$ \\
\hline $\mathrm{FDN}^{6}, \%$ da $\mathrm{MS}$ & $38,71 \pm 2,43$ & $38,77 \pm 2,88$ & $39,98 \pm 2,32$ \\
\hline $\mathrm{FDA}^{7}, \%$ da MS & $12,33 \pm 1,19$ & $12,29 \pm 1,44$ & $12,64 \pm 1,79$ \\
\hline Celulose $^{8}, \%$ da MS & $2,93 \pm 0,44$ & $1,66 \pm 0,25$ & $2,10 \pm 0,51$ \\
\hline Hemicelulose $^{9}, \%$ da MS & $26,38 \pm 1,65$ & $26,49 \pm 1,94$ & $27,35 \pm 1,79$ \\
\hline Lignina, $\%$ da MS & $9,40 \pm 0,86$ & $10,63 \pm 1,27$ & $10,47 \pm 2,12$ \\
\hline Cinzas, $\%$ da MS & $4,94 \pm 0,65$ & $5,15 \pm 0,66$ & $6,11 \pm 0,55$ \\
\hline
\end{tabular}


Amostras de cada forragem foram coletadas semanalmente e levadas a uma estufa de ventilação forçada a $65^{\circ} \mathrm{C}$ durante 72 horas para cálculo do teor de MS (AOAC, 2005), com o objetivo de se manter constante o valor nutritivo das dietas no transcorrer da pesquisa. Após a determinação do teor de $\mathrm{MS}$, as amostras de $\mathrm{Ci}$, $\mathrm{SC}$ e SM foram moídas em moinho tipo Wiley dotado com peneira de $1 \mathrm{~mm}$ (Wiley Mill; Arthur H. Thomas, Philadelphia, PA), e analisadas para determinação de PB, cinzas (AOAC, 2005) e FDN (Goering and Van Soest, 1970). Os resíduos de FDN foram analisados em sequência para determinação do teor de fibra em detergente ácido (FDA) e lignina (Goering and Van Soest, 1970). A concentração de celulose foi calculada pela diferença entre FDA - lignina, enquanto que o teor de hemicelulose foi determinado pela diferença entre FDN - FDA (Tabela 2).

Tabela 2. Composição nutricional das fontes de forragem ${ }^{1}$

\begin{tabular}{lccc}
\hline Item & Cana-de-açúcar in natura & Silagem de cana & Silagem de milho \\
\hline $\mathrm{MS}, \%$ & $33,38 \pm 3,06$ & $29,06 \pm 1,86$ & $32,07 \pm 1,90$ \\
$\mathrm{~PB}^{2}, \%$ da MS & $1,20 \pm 0,15$ & $1,81 \pm 0,19$ & $6,31 \pm 0,51$ \\
$\mathrm{FDN}^{3}, \%$ da MS & $59,24 \pm 3,45$ & $61,19 \pm 6,53$ & $56,78 \pm 2,12$ \\
$\mathrm{FDA}^{4}, \%$ da MS & $32,45 \pm 2,00$ & $34,17 \pm 3,93$ & $27,95 \pm 1,70$ \\
Celulose $^{5}, \%$ da MS & $20,42 \pm 2,42$ & $21,89 \pm 3,50$ & $13,06 \pm 1,90$ \\
Hemicelulose $^{6}, \%$ da MS & $26,80 \pm 1,58$ & $27,02 \pm 2,82$ & $28,83 \pm 1,18$ \\
Lignina, \% da MS & $12,03 \pm 1,30$ & $12,22 \pm 1,61$ & $14,87 \pm 2,01$ \\
Cinzas, \% da MS & $1,92 \pm 0,29$ & $3,86 \pm 1,19$ & $6,82 \pm 1,47$
\end{tabular}

${ }^{1}$ Médias $(n=10)$ e desvio padrão das análises nutricionais das fontes de forragem. ${ }^{2}$ Proteína bruta; ${ }^{3}$ Fibra em detergente neutro; ${ }^{4}$ Fibra em detergente ácido; ${ }^{5}$ Celulose $=$ FDA - lignina; ${ }^{6} \mathrm{Hemicelulose}=\mathrm{FDN}-\mathrm{FDA}$.

Coletaram-se amostras do oferecido das dietas experimentais de cada animal e baia coletiva a cada 14 dias, sendo em seguida congeladas a $-4^{\circ} \mathrm{C}$. Ao término da pesquisa, as amostras foram descongeladas em temperatura ambiente, agrupadas para formar uma amostra composta/fonte de forragem $/ 14$ dias, e levadas a uma estufa de ventilação forçada a $65^{\circ} \mathrm{C}$ durante 72 horas para cálculo do teor de MS (AOAC, 2005). Posteriormente, as amostras do oferecido das dietas foram moídas em moinho tipo Wiley dotado com peneira de $1 \mathrm{~mm}$ (Wiley Mill; Arthur H. Thomas, Philadelphia, PA) e analisadas para determinação de PB, cinzas (AOAC, 2005) e FDN (Goering and Van Soest, 1970). Os resíduos de FDN foram em seguida analisados quanto ao teor de FDA e lignina (Goering and Van Soest, 1970). $\mathrm{O}$ teor de celulose foi determinado pela diferença entre FDA - lignina, enquanto que a concentração de hemicelulose foi obtida pela diferença entre FDN - FDA (Tabela 1).

Amostras das sobras das dietas experimentais de cada animal e baia coletiva também foram coletadas a cada 14 dias e congeladas a $-4^{\circ} \mathrm{C}$. Ao término do experimento, as amostras foram descongeladas em temperatura ambiente, reunidas para formar uma amostra composta de cada tratamento/14 dias, e levadas a uma estufa de ventilação forçada a $65^{\circ} \mathrm{C}$ durante 72 horas para determinação do teor de MS (
O CMS foi determinado diariamente pela diferença entre a quantidade de MS oferecida e das sobras. O padrão de alimentação foi avaliado a cada 14 dias em quatro horários pós-alimentação (quatro, dez e 24 horas). Em cada tempo, a ração remanescente de cada animal alojado em baias individuais foi brevemente removida, pesada, e em seguida retornada ao seu respectivo animal. O padrão de alimentação foi determinado pelas seguintes equações:

CMS (0-4 horas) $=\mathrm{kg}$ de MS oferecidos no tempo zero menos $\mathrm{kg}$ de MS remanescentes às 4 horas pós-alimentação;

CMS (4-10 horas) $=\mathrm{kg}$ de MS remanescentes às 4 horas menos $\mathrm{kg}$ de MS remanescentes às 10 horas pós-alimentação;

CMS $(10-24$ horas $)=\mathrm{kg}$ de MS remanescentes às 10 horas menos $\mathrm{kg}$ de MS remanescentes às 24 horas pós-alimentação.

Ao longo de todo o período experimental, os animais foram pesados seis vezes a cada 14 dias após jejum de sólidos de 12 horas. Os 24 animais foram abatidos em um frigorífico localizado no município de Iporá/GO, dotado de Sistema de Inspeção Federal (SIF), após jejum de sólidos de doze horas. Após o abate, obteve-se o peso do trato gastrointestinal cheio e vazio, do fígado e das carcaças de cada animal para determinação do rendimento de carcaça quente. 
$\mathrm{O}$ delineamento experimental utilizado foi o inteiramente casualizado em esquema fatorial $3 \times$ 2 (três fontes de forragem e dois tipos de alojamento). Analisaram-se os dados pelo software R (R Core Team, 2014). Os dados foram analisados por um modelo misto de medidas duplicadas repetidas no tempo, considerando-se a fonte de forragem e alojamento como efeitos fixos e animal (quando os dados individuais foram disponíveis) como aleatório. No modelo incluiuse os efeitos de fonte de forragem (f), alojamento (a), dias de avaliação (d) e horas pós-alimentação (h), assim como as interações entre fonte de forragem (f) $\times$ dias de avaliação (d), fonte de forragem $(\mathrm{f}) \times$ horas pós-alimentação $(\mathrm{h})$, fonte de forragem (f) $\times$ dias de avaliação (d) $\times$ horas pósalimentação (h), alojamento (a) $\times$ dias de avaliação (d), alojamento (a) $\times$ horas pósalimentação (h), alojamento (a) $\times$ dias de avaliação $(d) \times$ horas pós-alimentação $(h)$, fonte de forragem (f) $\times$ alojamento (a), fonte de forragem (f) $\times$ alojamento (a) $\times$ dias de avaliação $(d)$, fonte de forragem (f) $\times$ alojamento (a) $\times$ horas pósalimentação $(\mathrm{h})$, dias de avaliação $(\mathrm{d}) \times$ horas pósalimentação (h) e fonte de forragem (f) $\times$ alojamento (a) $\times$ dias de avaliação (d) $\times$ horas pósalimentação (h), conforme a equação abaixo:

$\mathrm{y}_{\mathrm{ijk} k \mathrm{~m}}=\mu+\mathrm{f}_{\mathrm{i}}+\mathrm{a}_{\mathrm{j}}+\mathrm{d}_{\mathrm{k}}+\mathrm{h}_{1}+\mathrm{fd}_{\mathrm{ik}}+\mathrm{fh}_{\mathrm{il}}+\mathrm{fdh}_{\mathrm{ikl}}+$ $\mathrm{ad}_{\mathrm{jk}}+\mathrm{ah}_{\mathrm{jl}}+\mathrm{adh}_{\mathrm{jkl}}+\mathrm{fa}_{\mathrm{ij}}+\mathrm{fad}_{\mathrm{ijk}}+\mathrm{fah}_{\mathrm{ijl}}+\mathrm{dh}_{\mathrm{kl}}+$ $\mathrm{fadh}_{\mathrm{ijk} \mathrm{l}}+\mathrm{e}_{\mathrm{ijk} \mathrm{m} m}$; em que $\mathrm{y}=$ variável independente; $\mu=$ média; $\mathrm{e}=$ erro experimental.

Quando um efeito fixo foi significativo $(\mathrm{P} \leq$ $0,05)$ ou houve tendência de significância $(0,05 \leq$ $\mathrm{P} \leq 0,10)$, as médias foram comparadas pelo teste de Tukey. Os valores reportados nas tabelas de resultados correspondem às médias dos quadrados mínimos e erro padrão das médias (EPM).

\section{Resultados e Discussão}

Os resultados do CMS e conversão alimentar (CA) dos animais alojados em baias individuais estão descritos na Tabela 3. Não houve influência $(\mathrm{P}>0,05)$ da fonte de forragem sobre o CMS, expresso em $\mathrm{kg} / \mathrm{dia}$, \% do $\mathrm{PC}$ ou em gramas por unidade de tamanho metabólico $\left(\mathrm{PC}^{0,75}\right)$. Da mesma forma, observou-se que a CA também não foi alterada $(\mathrm{P}>0,05)$ pela fonte de forragem.

Estudos anteriores também relataram que não houve efeito da fonte de forragem (Ci ou SM) sobre o CMS (Fernandes et al., 2007, Macitelli et al., 2007), o que corrobora os dados obtidos no presente estudo. Ressalta-se que os níveis nutricionais das rações experimentais tanto no presente trabalho (Tabela 1) quanto nos experimentos reportados por Fernandes et al. (2007) e Macitelli et al. (2007) foram semelhantes, indicando que a fonte de forragem não é determinante sobre o CMS e CA, desde que os níveis nutricionais das dietas sejam semelhantes. Por outro lado, Roman et al. (2011) relataram que animais em confinamento alimentados com SM aumentaram o CMS comparado à SC, porém, neste caso, os níveis de FDN e carboidratos não fibrosos (CNF) na dieta à base de SM foram respectivamente de 36,7 e $42,6 \%$ do total da MS da ração, enquanto que os teores de FDN e CNF na dieta à base de $\mathrm{SC}$ foram de 42,1 e $37,4 \%$ do total da MS da ração, respectivamente. Portanto, o aumento do CMS nos animais alimentados com a dieta à base de SM no trabalho de Roman et al. (2011) pode ter sido causado pela variação nos níveis de FDN e CNF das duas dietas, e não exclusivamente pela fonte de forragem.

Muito se tem estudado a respeito dos fatores capazes de controlar o CMS, e consequentemente afetar o desempenho dos ruminantes. Porém, há um consenso que nenhum fator isolado é capaz de realizar este controle, mas sim que vários fatores atuam de forma associativa (Forbes, 1996). Receptores táteis na parede ruminal (Allen, 1996), variações nas concentrações e fluxos de nutrientes e de energia (Illius and Jessop, 1996) e o rendimento ótimo de energia líquida por unidade de oxigênio consumido (Ketelaars and Tolkamp, 1996) podem trabalhar em conjunto determinando o CMS. Isto significa que, mais do que a palatabilidade e digestibilidade de uma forragem, é fundamental conhecer a forma como essa forragem é oferecida em termos de tamanho médio de partículas, proporção entre os ingredientes e balanceamento nutricional da dieta, pois poderá haver influência sobre o CMS e consequentemente sobre o ganho de peso de bovinos de corte em confinamento.

No presente estudo, as dietas experimentais foram balanceadas para serem isonitrogenadas e isofibrosas. Embora a baixa digestibilidade da fibra potencialmente degradável da cana-deaçúcar pudesse levar à limitação da ingestão de MS (Pinto et al., 2009, Andrade et al., 2001), este fator não foi capaz de causar efeito sobre o CMS nas dietas com $\mathrm{Ci}$ ou SC.

$\mathrm{O}$ padrão de alimentação não foi alterado $(\mathrm{P}>$ $0,05)$ pela fonte de forragem nos animais alojados em baias individuais (Tabela 4). Entretanto, verificou-se um efeito de fonte de forragem $\times$ dias, 
no qual os animais alimentados com Ci reduziram $(\mathrm{P}<0,05)$ a quantidade de MS ingerida aos 42 dias após o início do experimento (Figura 1). Observou-se também uma resposta de fonte de forragem $\times$ tempo (horas pós-alimentação), sendo que neste caso os animais alimentados com SM aumentaram $(\mathrm{P}<0,05)$ a quantidade de MS consumida nas primeiras quatro horas pósalimentação em relação à Ci e $\mathrm{SC}$, ao passo que os animais alimentados com $\mathrm{Ci}$ aumentaram $(\mathrm{P}<$ 0,05) o CMS entre dez a 24 horas pósalimentação, comparados à SC e SM (Figura 2).
Independentemente da fonte de forragem, houve aumento $(\mathrm{P}<0,05)$ no $\mathrm{CMS}$ nas primeiras quatro horas pós-alimentação (5,4 kg de MS), comparado com os intervalos entre quatro a dez horas (4,3 $\mathrm{kg}$ de MS) e entre dez a 24 horas $(2,0$ $\mathrm{kg}$ de MS) (Tabela 4). Estudos prévios com vacas leiteiras também reportaram que o maior consumo de MS ocorreu nas primeiras quatro horas após o fornecimento da ração fresca no comedouro (Bhandari et al., 2008, Carvalho et al., 2012).

Tabela 3. Efeito da fonte de forragem sobre o consumo de matéria seca (CMS) e conversão alimentar (CA) nos animais alojados em baias individuais

\begin{tabular}{lccccccc}
\hline \multirow{2}{*}{ CMS $^{1}$} & \multicolumn{3}{c}{ Fonte de forragem } & EPM $^{5}$ & \multicolumn{3}{c}{ Valores de P } \\
\cline { 2 - 8 } & $\mathrm{Ci}^{2}$ & $\mathrm{SC}^{3}$ & $\mathrm{SM}^{4}$ & & Forragem $^{2}$ & Dias $^{6}$ & Forragem $\times$ dias \\
\hline CMS (kg/dia) & 11,9 & 11,1 & 11,8 & 0,6 & 0,62 & $<0,05$ & $<0,05$ \\
CMS (\% PC) & 2,0 & 2,1 & 2,2 & 0,07 & 0,47 & $<0,05$ & $<0,05$ \\
CMS (g/kg PC ${ }^{0,75}$ ) & 100,9 & 101,7 & 105,2 & 3,2 & 0,62 & $<0,05$ & $<0,05$ \\
CA (kg MS/ kg ganho) & 4,9 & 4,8 & 5,1 & 0,3 & 0,85 & $<0,05$ & $<0,05$ \\
\hline
\end{tabular}

${ }^{1}$ Consumo de matéria seca, ${ }^{2}$ Cana-de-açúcar in natura, ${ }^{3}$ Silagem de cana, ${ }^{4}$ Silagem de milho, ${ }^{5}$ Erro padrão da média, ${ }^{6}$ Dias de avaliação do CMS (1 a 70).

Não houve resposta $(\mathrm{P}>0,05)$ da fonte de forragem sobre $\mathrm{o} P \mathrm{PC}$ em todo $\mathrm{o}$ período experimental (Tabela 5), reforçando a hipótese de que a fonte de forragem não exerce influência sobre o desempenho animal, desde que os níveis nutricionais das dietas sejam semelhantes. Em outros estudos, o ganho de peso diário e o PC pré- abate também não foram alterados pela fonte de forragem (Fernandes et al., 2007), mesmo quando os níveis de FDN e CNF na dieta à base de SM foram respectivamente menores e maiores em relação à dieta com SC (Roman et al., 2011), o que teoricamente poderia resultar no maior ganho de peso nos animais alimentados com SM.

Tabela 4. Efeito da fonte de forragem sobre o padrão de alimentação nos animais alojados em baias individuais

\begin{tabular}{|c|c|c|c|c|c|c|c|c|c|c|c|}
\hline \multirow[b]{2}{*}{ Item } & \multirow[b]{2}{*}{$\begin{array}{c}\begin{array}{c}\text { Forra- } \\
\text { gem }\end{array} \\
\end{array}$} & \multirow[b]{2}{*}{ Dias $^{4}$} & \multicolumn{3}{|c|}{ Horas pós-alimentação } & \multirow[b]{2}{*}{$\mathrm{EPM}^{5}$} & \multicolumn{5}{|c|}{ Valores de $\mathrm{P}$} \\
\hline & & & $0-4$ & $4-10$ & $10-24$ & & $\begin{array}{c}\begin{array}{c}\text { Forra- } \\
\text { gem }\end{array} \\
\end{array}$ & Dias & Horas $^{6}$ & $\begin{array}{c}\text { Forragem } \times \\
\text { dias }\end{array}$ & $\begin{array}{c}\text { Forragem } \times \\
\text { horas }\end{array}$ \\
\hline \multirow{15}{*}{ 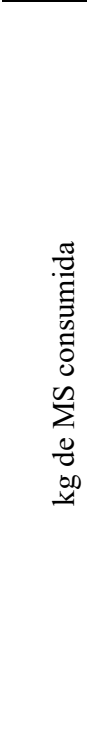 } & $\mathrm{Ci}^{1}$ & & 3,8 & 3,2 & 3,2 & & \multirow{15}{*}{0,51} & \multirow{15}{*}{$<0,05$} & \multirow{15}{*}{$<0,05$} & \multirow{15}{*}{$<0,05$} & \multirow{15}{*}{$<0,05$} \\
\hline & $\mathrm{SC}^{2}$ & 14 & 4,1 & 2,7 & 1,8 & 0,35 & & & & & \\
\hline & $\mathrm{SM}^{3}$ & & 6,0 & 3,2 & 1,3 & & & & & & \\
\hline & $\mathrm{Ci}$ & & 4,9 & 3,8 & 2,9 & & & & & & \\
\hline & $\mathrm{SC}$ & 28 & 5,1 & 3,8 & 1,7 & 0,32 & & & & & \\
\hline & SM & & 6,6 & 4,0 & 1,2 & & & & & & \\
\hline & $\mathrm{Ci}$ & & 3,8 & 3,2 & 2,7 & & & & & & \\
\hline & $\mathrm{SC}$ & 42 & 4,7 & 5,4 & 2,2 & 0,35 & & & & & \\
\hline & SM & & 7,0 & 4,5 & 0,5 & & & & & & \\
\hline & $\mathrm{Ci}$ & & 5,0 & 5,0 & 3,6 & & & & & & \\
\hline & $\mathrm{SC}$ & 56 & 5,2 & 5,0 & 2,8 & 0,30 & & & & & \\
\hline & SM & & 6,9 & 5,4 & 1,2 & & & & & & \\
\hline & $\mathrm{Ci}$ & & 4,6 & 4,9 & 1,4 & & & & & & \\
\hline & $\mathrm{SC}$ & 70 & 5,1 & 4,6 & 2,2 & 0,31 & & & & & \\
\hline & SM & & 6,7 & 5,5 & 0,5 & & & & & & \\
\hline
\end{tabular}

${ }^{1}$ Cana-de-açúcar in natura, ${ }^{2}$ Silagem de cana, ${ }^{3}$ Silagem de milho, ${ }^{4}$ Dias da avaliação $(14,28,42,56$ e 70$)$, ${ }^{5}$ Erro padrão da média, ${ }^{6}$ Horas pós-alimentação (0-4, 4-10, 10-24). 


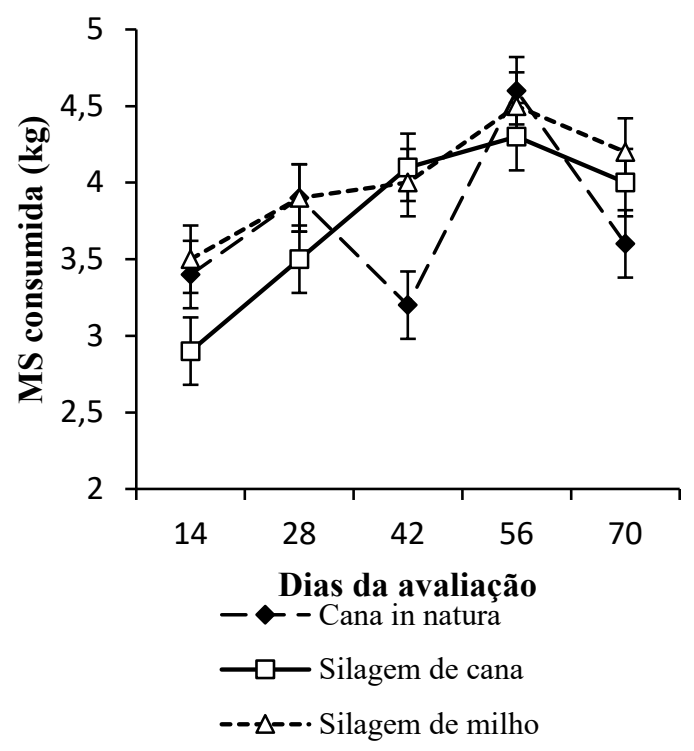

Figura 1. Efeito da fonte de forragem (Ci, SC ou SM) e dias de avaliação $(14,28,42,56$ e 70) sobre o padrão de alimentação ( $k g$ de MS consumidos).

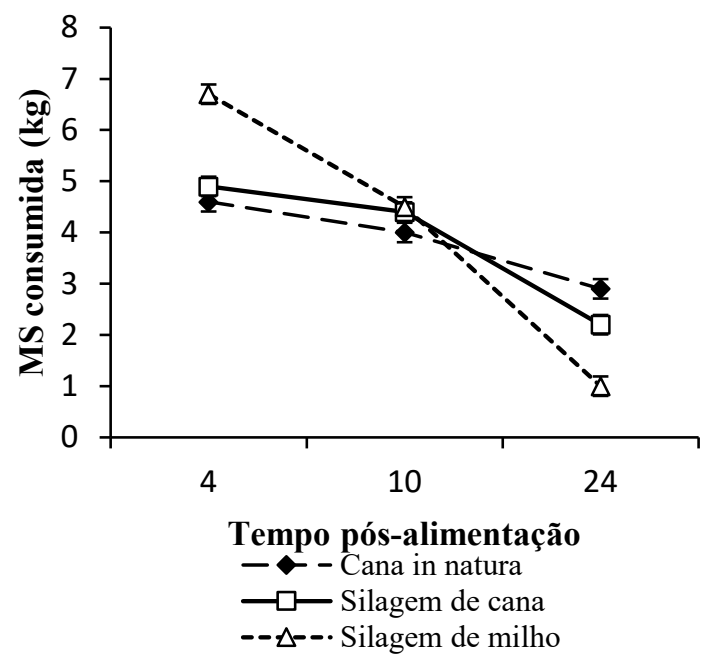

Figura 2. Efeito da fonte de forragem (Ci, SC ou SM) e horas pós-alimentação (0-4, 4-10 e 10-24) sobre o padrão de alimentação ( $\mathrm{kg}$ de MS consumidos).
O CMS exerce maior influência na resposta produtiva do que a digestibilidade dos componentes da dieta (Cabral et al., 2006). Assim, diferentes níveis de inclusão de forragens na ração podem resultar em variações no desempenho animal (Queiroz et al., 2008). Entretanto, desde que os parâmetros nutritivos (PB, energia e FDN) sejam ajustados para serem semelhantes ou muito próximos, como no presente estudo, espera-se que não haja diferenças no CMS e no ganho de peso, independente da fonte de forragem.

Houve tendência $(\mathrm{P}=0,09)$ de aumento do $\mathrm{PC}$ nos animais alojados em baias individuais em relação ao alojamento em baias coletivas (Tabela 5). No presente estudo, a área de cada baia coletiva era de $50 \mathrm{~m}^{2}$ (12,5 $\mathrm{m}^{2}$ /animal), e o comprimento dos comedouros em cada baia era de 3,8 metros lineares $(0,95 \mathrm{~m} /$ animal $)$, o que atende e até excede as recomendações de bem-estar para bovinos de corte em sistema de confinamento. No entanto, a competição pelo alimento nas baias coletivas, resultante da hierarquia social implícita no comportamento dos bovinos, provavelmente foi uma das causas da tendência $(P=0,09)$ de maior PC nos animais alojados em baias individuais. Resultados complementares a este estudo sobre as atividades de alimentação, ruminação e ócio (comportamento ingestivo) indicaram que os animais alojados em grupo despenderam mais tempo $(\mathrm{P}<0,05)$ em ócio $(38,9$ minutos/hora) e menos tempo $(\mathrm{P}<0,05)$ se alimentando (15,7 minutos/hora), ao passo que os animais alojados individualmente tiveram $\mathrm{O}$ comportamento oposto, ou seja, menor tempo $(\mathrm{P}<$ $0,05)$ despendido em ócio $(32,1$ minutos/hora) e maior tempo $(\mathrm{P}<0,05)$ gasto com alimentação (19,7 minutos/hora) (Broom and Molento, 2004).

Tabela 5. Efeito da fonte de forragem e tipo de alojamento sobre o peso corporal (PC)

\begin{tabular}{|c|c|c|c|c|c|c|c|c|c|c|c|}
\hline \multirow[b]{2}{*}{$\mathrm{PC}, \mathrm{kg}$} & \multicolumn{3}{|c|}{ Forragem } & \multicolumn{2}{|c|}{ Alojamento } & \multirow[b]{2}{*}{$\mathrm{EPM}^{4}$} & \multicolumn{5}{|c|}{ Valores de $\mathrm{P}$} \\
\hline & $\mathrm{Ci}^{1}$ & $\mathrm{SC}^{2}$ & $\mathrm{SM}^{3}$ & $\begin{array}{c}\text { Indivi- } \\
\text { dual }\end{array}$ & Cole-tivo & & $\begin{array}{c}\text { Forra- } \\
\text { gem }\end{array}$ & $\begin{array}{l}\text { Aloja- } \\
\text { mento }\end{array}$ & $\operatorname{Dias}^{5}$ & $\begin{array}{c}\text { Forragem } \times \\
\text { dias }\end{array}$ & $\begin{array}{l}\text { Forragem } \times \\
\text { alojamento }\end{array}$ \\
\hline Dia 1 & 449,5 & 442,1 & 450,6 & 471,4 & 423,4 & \multirow{6}{*}{26,2} & \multirow{6}{*}{0,97} & \multirow{6}{*}{0,09} & \multirow{6}{*}{$<0,05$} & \multirow{6}{*}{$<0,05$} & \multirow{6}{*}{0,41} \\
\hline Dia 14 & 495,5 & 473,9 & 491,9 & 512,8 & 461,4 & & & & & & \\
\hline Dia 28 & 531,0 & 519,1 & 520,5 & 549,2 & 497,9 & & & & & & \\
\hline Dia 42 & 550,3 & 551,4 & 551,3 & 576,5 & 525,4 & & & & & & \\
\hline Dia 56 & 585,1 & 588,3 & 574,4 & 609,1 & 556,1 & & & & & & \\
\hline Dia 70 & 628,5 & 624,6 & 605,3 & 649,2 & 589,8 & & & & & & \\
\hline
\end{tabular}

${ }^{1}$ Cana-de-açúcar in natura, ${ }^{2}$ Silagem de cana, ${ }^{3}$ Silagem de milho, ${ }^{4}$ Erro padrão da média, ${ }^{5}$ Dias da pesagem dos animais $(1,14$, $28,42,56$ e 70 ) 
Tabela 6. Efeito da fonte de forragem e tipo de alojamento sobre as características da carcaça

\begin{tabular}{|c|c|c|c|c|c|c|c|c|c|}
\hline \multirow[b]{2}{*}{ Item } & \multicolumn{3}{|c|}{ Forragem } & \multicolumn{2}{|c|}{ Alojamento } & \multirow[b]{2}{*}{$\mathrm{EPM}^{4}$} & \multicolumn{3}{|c|}{ Valores de $\mathrm{P}$} \\
\hline & $\mathrm{Ci}^{1}$ & $\mathrm{SC}^{2}$ & $\mathrm{SM}^{3}$ & $\begin{array}{c}\text { Indivi- } \\
\text { dual }\end{array}$ & $\begin{array}{c}\text { Cole- } \\
\text { tivo } \\
\end{array}$ & & $\begin{array}{c}\text { Forra- } \\
\text { gem }\end{array}$ & $\begin{array}{l}\text { Aloja- } \\
\text { mento }\end{array}$ & $\begin{array}{l}\text { Forragem } \times \\
\text { alojamento }\end{array}$ \\
\hline PC pré-abate, $\mathrm{kg}$ & 628,5 & 624,6 & 605,3 & 649,2 & 589,8 & 28,8 & 0,83 & 0,09 & 0,45 \\
\hline $\begin{array}{l}\text { Peso da carcaça } \\
\text { quente, } \mathrm{kg}\end{array}$ & 329,7 & 331,0 & 323,7 & 343,7 & 312,5 & 17,3 & 0,95 & 0,13 & 0,52 \\
\hline $\begin{array}{l}\text { Rendimento de } \\
\text { carcaça quente, \% }\end{array}$ & 52,4 & 52,9 & 53,5 & 52,9 & 52,9 & 0,6 & 0,42 & 0,97 & 0,11 \\
\hline $\begin{array}{l}\text { Trato gastrintestinal } \\
\text { cheio, kg }\end{array}$ & 56,1 & 56,4 & 50,1 & 58,1 & 50,3 & 3,3 & 0,35 & 0,06 & 0,16 \\
\hline $\begin{array}{l}\text { Trato gastrintestinal } \\
\text { vazio, } \mathrm{kg}\end{array}$ & 11,7 & 11,3 & 10,2 & 11,9 & 10,2 & 0,7 & 0,29 & $<0,05$ & 0,21 \\
\hline Peso do fígado, $\mathrm{kg}$ & 7,0 & 6,5 & 6,9 & 7,1 & 6,4 & 0,3 & 0,46 & 0,07 & 0,48 \\
\hline
\end{tabular}

A segunda provável causa da tendência ( $\mathrm{P}$ $=0,09)$ de aumento do PC nos animais alojados em baias individuais pode ter sido o aumento da temperatura ambiente nas baias coletivas, as quais eram desprovidas de sombra. Ainda que o alojamento individualizado seja economicamente impraticável em sistemas de confinamento, os dados obtidos no presente estudo evidenciam que a adoção de estratégias adicionais de bemestar animal, tais como a instalação de sombreamento artificial ou mesmo o plantio de árvores entre as baias pode promover diferenças no desempenho produtivo em bovinos confinados. $\mathrm{O}$ sombreamento artificial $\left(0 ; 2 ; 3,3\right.$ e $4,7 \mathrm{~m}^{2} /$ animal $)$ com sombrites instalados no interior de baias coletivas no sentido norte-sul aumentou o bem-estar animal e o desempenho de 126 animais da raça Angus alimentados com a mesma dieta (Sullivan et al., 2011). Assim, pesquisas adicionais com maior número de animais alojados em baias individuais ou coletivas são necessárias para confirmar os achados obtidos no presente estudo em relação ao desenvolvimento corporal.

Os resultados de características da carcaça estão expressos na Tabela 6 . Não houve efeito $(\mathrm{P}>0,05)$ de forragem sobre as características avaliadas, confirmando a hipótese de que a fonte de forragem não exerce influência sobre o desempenho animal desde que os níveis nutricionais da dieta sejam semelhantes. Resultados semelhantes aos obtidos nesta pesquisa sobre as características da carcaça foram reportados por Fernandes et al. (2008) ao alimentarem animais da raça Canchim com dietas à base de $\mathrm{Ci}$ ou SM.

Houve resposta $(\mathrm{P}<0,05)$ de alojamento sobre o peso do trato gastrintestinal vazio e tendência de aumento $(0,05 \leq \mathrm{P} \leq 0,10)$ do $\mathrm{PC}$ pré-abate, peso do trato gastrintestinal cheio e peso do fígado nos animais alojados em baias individuais em relação às baias coletivas (Tabela 6). As prováveis causas do efeito de alojamento são as mesmas já discutidas anteriormente em relação aos dados da Tabela 5 (competição pelo alimento nas baias coletivas oriunda da hierarquia social inerente ao comportamento dos bovinos e ambiência mais favorável devido ao sombreamento nas baias individuais).

\section{Conclusões}

A $\mathrm{Ci}, \mathrm{SC}$ e $\mathrm{SM}$ podem ser recomendadas na alimentação de bovinos de corte em confinamento por não terem apresentado diferenças no CMS e ganho de peso corporal. Outros fatores podem ser determinantes na escolha da fonte de forragem, tais como o custo de produção por unidade de MS ou a aptidão do produtor rural.

Pesquisas adicionais com maior número de animais alojados em baias individuais ou coletivas são necessárias para confirmar os resultados reportados nesta pesquisa em relação ao ganho de peso corporal.

\section{Agradecimentos}

Os autores deste trabalho agradecem ao médico pecuarista Dr. Esmar Gonçalves da Cunha pelo empréstimo dos 24 animais utilizados neste 
experimento, assim como à PROCRIA Saúde e Nutrição Animal pela mistura dos ingredientes da ração concentrada.

\section{Referências Bibliográficas}

Allen, M. S. 1996. Physical constraints on voluntary intake of forages by ruminants. Journal of Animal Science, 74, 3063-3075.

Andrade, J. B., Júnior, E. F., Possenti, R. A., Leinz, F. F., Bianchini, D. \& Carvalho, C. F. R. 2001. Valor nutritivo da cana-de-açúcar na forma de silagem ou" in natura". Boletim de Indústria Animal, 58, 135-143.

ANUALPEC. 2016. Anuário da Pecuária Brasileira, 20th edn. Instituto FNP, São Paulo, SP, Brasil.

AOAC. 2005. - Association Official Analytical Chemist (2005), Official Methods of Analysis (18th ed.) edn. AOAC, Gaitherburg, Maryland, USA.

Azevêdo, J. A. G., Pereira, J. C., Carneiro, P. C. S., Queiroz, A., Barbosa, M. H. P., Fernandes, A. M. \& Rennó, F. P. 2003. Avaliação da divergência nutricional de variedades de canade-açúcar (Saccharum spp.). Revista Brasileira de Zootecnia, 32, 1431-1442.

Berchielli, T. T., Pires, A. V. \& Oliveira, S. G. 2011. Nutrição de Ruminantes. FUNEP, Jaboticabal, Brazil.

Bhandari, S. K., Li, S., Ominski, K. H., Wittenberg, K. M. \& Plaizier, J. C. 2008. Effects of the Chop Lengths of Alfalfa Silage and Oat Silage on Feed Intake, Milk Production, Feeding Behavior, and Rumen Fermentation of Dairy Cows. Journal of Dairy Science, 91, 1942-1958.

Brondani, I. L., Sampaio, A. A. M., Restle, J., Bernardes, R., Pacheco, P. S., Freitas, A. K., Kuss, F. \& Peixoto, L. A. O. 2004. Aspectos quantitativos de carcaças de bovinos de diferentes raças, alimentados com diferentes níveis de energia. Revista Brasileira de Zootecnia, 33, 978-988.

Broom, D. M. \& Molento, C. F. M. 2004. Animal welfare: concept and related issues-review. Archives of Veterinary Science, 9, 1-11.

Cabral, L. S., Filho, S. d. C. V., Detmann, E., Malafaia, P. A. M., Zervoudakis, J. T., de Souza, A. L., Veloso, R. G. \& Nunes, P. M. M. 2006. Consumo e digestibilidade dos nutrientes em bovinos alimentados com dietas à base de volumosos tropicais. Revista Brasileira de Zootecnia, 35, 2406-2412.
Campos, P. R. S. S., Valadares Filho, S. C., Detmann, E., Cecon, P. R., Leão, M. I., Lucchi, B. B., Souza, S. M. \& Pereira, O. G. 2010. Consumo, digestibilidade e estimativa do valor energético de alguns volumosos por meio da composição química. Revista Ceres, 57, 79-86.

Carvalho, E. R., Schmelz-Roberts, N. S., White, H. M., Wilcox, C. S., Eicher, S. D. \& Donkin, S. S. 2012. Feeding behaviors of transition dairy cows fed glycerol as a replacement for corn. Journal of Dairy Science, 95, 7214-7224.

Costa, M. G., Campos, J. M. S., Valadares Filho, S. C., Valadares, R. F. D., Mendonça, S. S., Souza, D. P. \& Teixeira, M. P. 2005. Desempenho produtivo de vacas leiteiras alimentadas com diferentes proporções de cana-de-açúcar e concentrado ou silagem de milho na dieta. Revista Brasileira de Zootecnia, 34, 2437-2445.

Fernandes, A. R. M., Sampaio, A. A. M., Henrique, W., Oliveira, E. A., Tullio, R. R. \& Perecin, D. 2008. Características da carcaça e da carne de bovinos sob diferentes dietas, em confinamento. Arquivo Brasileiro de Medicina Veterinária e Zootecnia, 60, 139-147.

Fernandes, A. R. M., Sampaio, A. A. M., Henrique, W., Perecin, D., OLIVEIRA, E. \& Túllio, R. R. 2007. Avaliação econômica e desempenho de machos e fêmeas Canchim em confinamento alimentados com dietas à base de silagem de milho e concentrado ou cana-deaçúcar e concentrado contendo grãos de girassol. Revista Brasileira de Zootecnia, 36, 855-864.

Forbes, J. M. 1996. Integration of regulatory signals controlling forage intake in ruminants. Journal of Animal Science, 74, 3029-3035.

Freitas, A. W. P., Pereira, J. C., Rocha, F. C., Detmann, E., Ribeiro, M. D., Costa, M. G. \& Leonel, F. d. P. 2006. Características da silagem de cana-de-açúcar tratada com inoculante bacteriano e hidróxido de sódio e acrescida de resíduo da colheita de soja. Revista Brasileira de Zootecnia, 35, 48-59.

Goering, H. K. \& Van Soest, P. J. 1970. Forage fiber analyses (apparatus, reagents, procedures, and some applications). US Agricultural Research Service Washington, DC.

Huhtanen, P., Asikainen, U., Arkkila, M. \& Jaakkola, S. 2007. Cell wall digestion and passage kinetics estimated by marker and in situ methods or by rumen evacuations in cattle 
fed hay 2 or 18 times daily. Animal Feed Science and Technology, 133, 206-227.

Illius, A. W. \& Jessop, N. S. 1996. Metabolic constraints on voluntary intake in ruminants. Journal of Animal Science, 74, 3052-3062.

Ketelaars, J. J. \& Tolkamp, B. J. 1996. Oxygen efficiency and the control of energy flow in animals and humans. Journal of Animal Science, 74, 3036-3051.

Macitelli, F., Berchielli, T. T., Morais, J. A. S., Silveira, R. N. \& Canesin, R. C. 2007. Desempenho e rendimento de carcaça de bovinos mestiços alimentados com diferentes volumosos e fontes protéicas. Revista Brasileira de Zootecnia, 36, 1917-1926.

Mertens, D. R. 1987. Predicting intake and digestibility using mathematical models of ruminal function. Journal of Animal Science, 64, 1548-1558.

Moreira, F. B. \& Prado, I. N. 2010. Sazonalidade na produção e qualidade de plantas forrageiras. In: Prado, I. N. (ed.) Produção de bovinos de corte e qualidade da carne. Eduem, Maringá, Paraná, Brasil.

Moreira, F. B., Prado, I. N., Cecato, U., Wada, F. Y. \& Mizubuti, I. Y. 2004. Forage evaluation, chemical composition, and in vitro digestibility of continuously grazed star grass. Animal Feed Science and Technology, 113, 239-249.

Pinto, A. P., Nascimento, W. G., Abrahão, J. J. S., Perotto, D., Moletta, J. L. \& Lugão, S. M. B. 2009. Digestibilidade, consumo, desempenho e características de carcaça de tourinhos mestiços confinados com cana-de-açúcar ou silagem de sorgo. Revista Brasileira de Zootecnia, 38, 2258-2263.

Queiroz, O. C. M., Nussio, L. G., Schmidt, P., Ribeiro, J. L., Santos, M. C. \& Zopollatto, M.
2008. Silagem de cana-de-açúcar comparada a fontes tradicionais de volumosos suplementares no desempenho de vacas de alta produção. Revista Brasileira de Zootecnia, 37, 358-365.

Roman, J., Jobim, C. C., Resende, F. D., Siqueira, G. R., Faria, M. H. \& Oliveira Neto, R. A. 2011. Performance of finishing beef cattle fed different diets containing whole-crop maize silage or sugarcane silage. Revista Brasileira de Zootecnia, 40, 682-689.

Sullivan, M. L., Cawdell-Smith, A. J., Mader, T. L. \& Gaughan, J. B. 2011. Effect of shade area on performance and welfare of short-fed feedlot cattle. Journal of Animal Science, 89, 2911-2925.

Velho, J. P., Mühlbach, P. R. F., Nörnberg, J. L., Velho, I. M. P. H., Genro, T. C. M. \& Kessler, J. D. 2007. Composição bromatológica de silagens de milho produzidas com diferentes densidades de compactação. Revista Brasileira de Zootecnia, 36, 1532-1538.

Zopollatto, M., Daniel, J. L. P. \& Nussio, L. G. 2009. Aditivos microbiológicos em silagens no Brasil: revisão dos aspectos da ensilagem e do desempenho de animais. Revista Brasileira de Zootecnia, 38, 170-189.

\footnotetext{
Article History:

Received 31 March 2017

Accepted 18 April 2017

Available on line 11 May 2017

License information: This is an open-access article distributed under the terms of the Creative Commons Attribution License 4.0, which permits unrestricted use, distribution, and reproduction in any medium, provided the original work is properly cited.
} 